\title{
A Contrastive Study on the Application of Mind Maps in Argumentative Writing Instruction for EFL Learners
}

\author{
Ying Zhang ${ }^{1}$ \\ ${ }^{1}$ English Department, North China Electric Power University, Baoding, Hebei Province, China \\ Correspondence: Ying Zhang, English Department, North China Electric Power University, Baoding, Hebei \\ Province, China.
}

\author{
Received: October 1, 2018 Accepted: November 12, 2018 Online Published: November 16, 2018 \\ doi: 10.5539/elt.v11n12p93 URL: https://doi.org/10.5539/elt.v11n12p93
}

\begin{abstract}
This study is aimed at exploring the relationship between explicit instruction of mind mapping at pre-writing stage and the quality of Chinese EFL learners' argumentative writing. Thirty-nine first-year English majors from two convenient classes were randomly assigned into the experimental group and the control group respectively. For the control group, the traditional way of teaching writing was adopted, while for the experimental group, the application of mind mapping was integrated into the writing instruction. Five participants from the experimental group participated in the following interview. The comparison of mean scores of post-experimental argumentative writings between two groups indicated that the experimental group significantly performed better than the control group in content and organization of their writings. Through the analysis of interviews, it was found that participants regarded mind mapping as a useful tool for planning their writing and their personal attitudes toward English writing became more positive. The findings provide EFL teachers and curriculum designers with useful insights into improving the efficiency of writing instruction.
\end{abstract}

Keywords: mind maps, EFL learners, argumentative writing, writing instruction

\section{Introduction}

Writing plays a significant part in communication. It is a comprehensive manifestation of one's language competence and logical thinking. Writing is an output process that reflects writers' use of their stored knowledge to convey meanings to readers. Both the learned knowledge and the ability to use the useful information are involved in the writing process. A good English writing is quite demanding for writers, especially for EFL learners. On one hand, writing involves a complex process which requires that EFL learners activate both their cognitive and linguistic knowledge that they may feel less confident and insufficient (Peregoy \& Boyle, 2005). They often feel tortured by their lack of vocabulary, unclear ideas and incoherent organization of contents. A lot of Chinese EFL learners feel that they just don't have relevant thoughts or supporting ideas in writing. On the other hand, students are not provided with necessary writing skills in traditional writing instruction, which may worsen the situation. Consequently, learners experience frustration and a low level of motivation associated with the writing process which make them uninterested in practicing English writing except for exams needs. For teachers, it is extremely challenging and time-consuming to teach writing. In most English classes, the traditional method of teaching writing is adopted by many teachers, in which students are required to receive sufficient language input to develop their writing abilities, especially when they are preparing for exams. Therefore, in class, teachers spend a lot of time analyzing model essays and pay more attention to students' writing results, but not to the writing process. For example, for many Chinese EFL learners, reciting sample essays is regarded as a very effective way to improve their performance in writing. However, as a complex cognitive process, writing requires learner to use a combination of skills, such as developing, analyzing and interpreting ideas. EFL learners should be exposed to necessary writing strategies to enable them to think and communicate through the written language. Obviously, the current writing instruction fails to provide learners with due support in the writing process. Besides, the important roles of brainstorming at the pre-writing stage and the necessity of integrating writing strategy training in instruction to promote learners' development of writing abilities are often neglected by teachers (Bejarano et al., 1997).

In fact, one's focus of attention and ability of information-processing are greatly restricted by his limited level of cognition when performing a complex task (Skehan \& Foster, 2001). Pre-writing stage provides learners with 
opportunities and time to put their ideas down on paper before beginning to get started with the actual writing task. It helps learners activate their prior knowledge and search for the stored knowledge and needed information (Rao, 2007), which effectively lessens students' burden of cognitive processing needed in writing and enhances the quality of language production. Proficient writers tend to make careful plans before writing, such as establishing writing goals, organizing their thoughts and considering the needs of audience (Bereiter \& Scardamalia, 1987; Flower \& Hayes, 1981; Sunseri, 2011). In addition,"brainstorming activities motivate students who do not usually want to write by creating a nonthreatening atmosphere" (Scane et al., 1991, p.14). Thus, with the lowered level of anxiety, students' writing motivation is highly activated which is beneficial for their development of writing abilities. While in writing practice, the employment of different types of brainstorming activities before writing may play various roles in the actual writing process. However, there is a gap in studying the various roles of pre-tasks in L2 writing in previous research (Ojima, 2006), and relatively few studies focused on the specific effects brought by a particular type of brainstorming activity.

\section{Mind-Mapping and L2 Writing}

As a major brainstorming activity, the concept of mind maps was first put forward by Tony Buzan in 1960s. It has been viewed as a visual representation tool for the abstract thoughts and information stored in one's mind, which facilitates human being's thinking and learning process. Mind maps make our hidden ideas or thoughts become visible to people. They also indicate different relationships between meaningful items, events and actions through connecting links or arrows (Novak \& Canas, 2008). This indicates the potential of using mind maps as a tool for learners to establish and organize the interconnections between ideas and concepts.

In writing process, as a graphic visual aid, mind maps demonstrate a writer's ideas towards a certain topic as well as how the ideas are connected to each other (Sturm \& Rankin-Erickson, 2002). Constructing mind maps is a process of thinking on papers, which provides a way of helping writers generate ideas, visualize and organize their thoughts in a clear and logical way before the actual writing. In mind mapping, writers' divergent thinking is generated and all the materials needed are selected and arranged briefly on the paper in advance. When start writing, they already have a clear goal and direction, which effectively alleviates writers' cognitive burden for processing complex information during writing. According to Constructivism, all the knowledge is built upon learners' prior knowledge and their existed experiences, and learners should be able to identify their current knowledge and their needs for further learning. It means in the cognitive process, learners always associate their known information with the unknown to make learning happen. And mind mapping facilitates learners' construction of such connections explicitly. It offers learners opportunities to activate their previous knowledge and experiences as an assistance to help establish meaningful links between the old and the new which are of great help to gain deeper insights into a certain topic.

English writing is a big headache for EFL learners and many of them complain about writer's block. As Hedge (2000) put forward, one of the most difficult tasks in writing was how to get started. It also happens that EFL learners forget their original ideas and have no ideas about what to write about when they are committed to racking their brains with the use of language expressions. Studies on pre-writing indicate that there is a positive relationship between time spent on planning tasks before writing and the quality of L2 writing (Johnson et al, 2012). Mind maps direct writers' attention to important ideas and help them organize useful information into a systemic structure. It's found that the use of mind mapping can also improve writers' self regulation in writing process (Talebinezhad \& Negari, 2007). EFL learners who receive mind mapping training in writing instruction tend to outperform others who don't in writing production (Pishgadam \& Ghanizadeh, 2006; Negari, 2011). In addition to the improvement of writers' overall writing performance, Ojima (2006) found that the use of mind maps helped improve Japanese EFL writers' writing complexity and fluency. Shu (2009) investigated effects of applying mind mapping on college non-English majors' writing performance. It was found that participants' written structure, content and language were improved. The studies about the influence of mind mapping on Chinese EFL learners' writing development are focused on theoretical discussions, while empirical studies about applying mind maps to college EFL learners' writing instruction are limited in number. On the basis of the previous research, this study is aimed at exploring the relationship between the application of mind mapping at the pre-writing stage and the development of EFL writers' writing abilities and how to integrate mind mapping into Chinese EFL writing instruction.

\section{Method}

\subsection{Participants}

The study was conducted among 44 first-year college English major students (ages 18 to 20) coming from two intact classes. The two classes were convenient samples which were taught by one teacher with same teaching 
materials and teaching periods. They were randomly assigned to the experimental group and the control group respectively. In the experimental group which consists of 17 female students and 5 male students, mind mapping as a pre-writing task was applied in the in-class instruction. In the control group which consists of 19 female students and 3 male students, the traditional teaching method was employed. At the end of this experiment, the argumentative writings of 39 participants who completed all the writing tasks were used for further analysis. According to their scores of English test in college entrance examination, their English proficiency levels are no significant difference. A pre-experimental writing test also showed no significant difference between participants' writing abilities in the two groups. At the time of experiment, the participants were in their first semester of English writing course which was scheduled 8 weeks with two periods in each week.

\subsection{Instrument}

Pre-experimental and post-experimental writing tests were designed to examine the effects of employing mind maps in writing instruction and the differences between the two groups. On basis of the analysis of the writing tests, a semi-structured interview was conducted to find out participants' attitudes toward the application of mind mapping in writing class.

The pre-experimental writing test was conducted to make sure that there was no obvious difference on participants' writing proficiency between the two groups. Both of the two writing tests were argumentative writings which were selected respectively from the writing tasks in Tests for English majors Band 4 to ensure the two tasks were on the same difficulty level. All the participants were required to accomplish the writing tests within 50 minutes under test conditions. All the writing essays were marked by two experienced teachers independently who were blind to the purpose of the study and were unaware of the distinction of the two groups. Participants' writing essays were marked in three aspects of organization, content, the use of language according to the Score Level Criteria (Jacobs et al., 1981). The scores given by the two teachers were averaged to confirm the participants' final performance on writing.

The interview was arranged after the post-experimental writing test. Five participants selected randomly from the experimental group were interviewed about their writing process and their attitudes toward using mind mapping in writing tasks. The interview was designed as semi-structured and was conducted in the form of Chinese.

\subsection{Experimental Procedures}

Except for the time assigned for the two tests, there were seven weeks all together to implement the experiment. In each week, all the participants spent two periods learning writing. For the control group, the traditional way of teaching writing was employed in which students were informed of the basic writing skills of each unit and then were required to practice these skills in drafting their own writing essays, and after they had accomplished, the teacher would mark their papers and gave comments on their writing. For the experimental group, students were exposed to the mind mapping activities as the pre-writing task before they got started with the actual writing.

To be specific, in the first lecture of the experiment, the teacher introduced the concept of mind mapping and exemplified how to employ mind mapping to generate and organize ideas. Then students were encouraged to make their own mind maps from perspective of writing content, organization and language according to different topics in small groups with the guidance of the teacher. After the practice, they were assigned new tasks to make mind maps themselves. Then, in the following each lecture, students were assigned 15 minutes to make plans and preparations about writing topic through mind mapping as the pre-writing activity. Then they were allowed 35 minutes to accomplish their writing work. After that, the evaluation and comments were given by the teacher.

\subsection{Data Analysis}

All the quantitative data collected from the two writing tests were summarized and analyzed through SPSS 16.0. To find out whether there is any difference between the two groups in pre-test and post-test, independent samples T-test was used for further analysis. To investigate the effects of mind mapping on participants' writing performance, the data of participants' writing performance from the three perspectives of content, organization and language in the experimental group and the control group were further analyzed. The qualitative data gathered from the following interview were transcribed and analyzed by the researcher of the present study.

\section{Result}

\subsection{The Mean Scores of Pre-experimental Writing Test}

All the participants come from convenient samples of two intact classes, so it is necessary to make sure whether there is any difference on their writing abilities before the present experiment. Therefore, independent T-test was conducted to analyze their scores in the pre-test. 
Table 1. Descriptive statistics of independent T-test on the score of pre-test of two groups

\begin{tabular}{llllll}
\hline Group & N & Mean & SD & T-value & Sig. \\
\hline Experi. Group & 22 & 69.67 & 5.35 & & \\
Contr. Group & 22 & 69.82 & 5.29 & -.064 & .960 \\
\hline
\end{tabular}

* t-value is significant at the level of 0.05 .

As shown in Table 1, the mean score of the participants in the experimental group in the pre-test was 69.67, and that of the control group was 69.82. Through t-test $(t=-.064, p=.960>.05)$, it was found that there was no significant difference between the two groups in terms of their English writing proficiency levels. Thus, the two groups were at the same level of writing abilities and they were homogeneous participants.

\subsection{The Mean Scores of Post-experimental Writing Test}

\subsubsection{The Average Mean Score of Post-test between the Two Groups}

As shown in Table 2, the participants' mean score in the post-test writing (mean=75.23) in the experimental group improved significantly after the experiment $(\mathrm{t}=-2.11, \mathrm{p}=.040<.05)$. In the control group, the mean score was also higher than that in the pre-test (mean $=70.03, \mathrm{p}=.089>.05$ ), but this improvement was not obvious. In order to identify whether there was significant difference on participants' writing performance in the post-test between the two groups, t-test was used for further analysis. Table 2 showed that there was a significant difference in the mean scores of post-test writing between the two groups, and experimental group outperformed the control group $(\mathrm{t}=2.08, \mathrm{p}=.045<.05)$ as a whole.

Table 2. Descriptive statistics on the scores of pre-test and post-test

\begin{tabular}{llllllll}
\hline & & Mean & SD & T-value & Sig. & T-value & Sig. \\
\hline Experi. Group & pre-test & 69.67 & 5.35 & & & & \\
& post-test & 75.23 & 4.63 & $-2.11^{*}$ & .040 & & \\
Contr. Group & pre-test & 69.82 & 5.29 & & & & \\
& post-test & 70.03 & 5.10 & -.43 & .089 & $2.08^{*}$ & .045 \\
\hline
\end{tabular}

*t-value is significant at the level of 0.05 .

\subsubsection{Comparisons Between the Two Groups in Mean Scores of Content, Organization and Language}

Comparisons between the experimental group's and the control group's writing performance in terms of content, organization and language in their post-test writing were made to find out whether there was any difference. Table 3 showed the mean scores and standard deviations of the three main criteria of writing quality of the two groups. T-test was employed for further analysis.

Table 3. Descriptive Statistics on the scores of pre-test and post-test for the control group

\begin{tabular}{llllll}
\hline & & Mean & SD & t-value & Sig. (2-tailed) \\
\hline \multirow{2}{*}{ Content } & Experi. Group & 26.15 & 4.21 & \multirow{2}{*}{$3.32^{*}$} & .007 \\
\multirow{3}{*}{ Organization } & Contr. Group & 24.11 & 5.23 & & \\
& Experi. Group & 27.41 & 4.55 & \multirow{2}{*}{$4.01^{*}$} & .004 \\
Language & Contr. Group & 24.34 & 4.99 & & \\
& Experi. Group & 21.67 & 5.14 & \multirow{2}{*}{.47} & .650 \\
\hline
\end{tabular}

*t-value is significant at the level of 0.05 .

It is indicated that the mean scores of writing content $(t=3.32, p=.007)$ and organization $(t=4.01, p=.004)$ held 
by the experimental group were significantly higher than those held by the control group. While the mean score of the language use for the experimental group was 21.67 which is higher than that for the control group (mean $=21.58, \mathrm{p}=.650>.05)$, but this difference was not significant. This suggested that the experimental group performed significantly better on content and organization in their post-test argumentative writing than those of the control group, but the difference in language used in writing between the two groups was not obvious.

\subsection{Qualitative Data from the Interview}

After the post-test, five participants from the experimental group were interviewed about their writing process and attitudes toward the application of mind mapping in writing class. The following questions were designed as a guideline to carry out the interview.

1) Do you think it is helpful to draw mind maps before getting started with the actual writing task? If yes, how is it helpful?

2) What are your problems or difficulties in using mind mapping?

3) What's your attitude towards English writing? Anything different from your former writing experiences?

For the first question, all the five interviewees gave a positive response. For them, mind maps were viewed as useful tools that could help them get a better understanding of the writing task and search for important ideas in memory to generate more creative ideas. During the process of drawing mind maps, students thought about how to organize ideas into different categories. Some student also mentioned that mind map functioned as a reminder of important meanings while they were struggling with the linguistic resources.

Yes. It gives me time to come up with more ideas and organize them in different parts in my writing. Thus, I feel ready for the following writing task. (Student A)

Yes. Mind map helps me put down previous useful information related to the present topic and I won't forget important ideas in writing process while I am thinking about the language. (Student B)

Yes. It seems that I don't feel anxious about nothing to write about the topic. Now I have lots of things to put down. (Student C)

When talking about the problems of using mind maps in practice, three interviewees mentioned that they had to spend longer time applying mind mapping to writing. Two interviewees also talked about the difficulties of categorizing the ideas generated in mind mapping.

Well, I feel 50 minutes are not enough. Usually I have to spend more time drawing mind maps, and then I don't have enough time writing the essay, especially in a test. (Student B)

The problem, yes. Sometimes I am not sure whether an idea should be put under one category or another because it seems that there are overlaps or something. (Student D)

Yes, I have the similar problem with them. I don't have enough time for mind mapping and I just can't make up my mind to decide on how to use the relevant information. (Student $\mathrm{E}$ )

Then, the interviewees were encouraged to talk about attitudes towards their experience of English writing. From their responses, a change in their attitudes toward English writing could be identified. Some reported more confidence and an increasing interest in conveying their ideas about different topics to readers in writing. With the employment of mind mapping at the pre-writing stage, English writing was no longer regarded as an impossible mission for them.

Before attending this course, writing is the most difficult English learning task for me. Mind mapping allows me to list my points and I can develop ideas more easily in writing. So English writing seems not so difficult to me. (Student A)

I didn't like English writing before because it was a torturing process. But it's interesting to get started with what I am familiar with and mind mapping, and now I think English writing is not so boring. (Student $C$ )

My problem with English writing is that I don't have much to say about the topic. Now I can come up with a lot of ideas through it (mind mapping), and I can also write my points that are related to the topic. I feel more confident in my writing. I am happy with it. (Students D)

\section{Discussion}

The present study explored the effects of mind mapping at the pre-writing stage on EFL writing. The findings revealed that explicit instruction of mind mapping could help Chinese EFL learners improve their argumentative writing performance, especially on contents and organization. This is consistent with the findings in previous 
research that the application of mind mapping plays a positive role in learners' development of writing proficiency (Lee \& Cho, 2010; Lee, 2013; Ojima, 2006; Shu, 2009). In the process of drawing mind maps, learners get access to opportunities of activating their prior knowledge and experiences, establishing connections between different ideas, and organizing these information into a coherent whole. All of these activities in planning facilitate learners' actual writing process. As Kellogg (1990) put forward that mind mapping at the pre-writing stage effectively lessens the overload on writers in writing process. Therefore, it helps improve learners' writing performance.

In this study, no correlation is found between the application of mind mapping and the improvement of language use in writing. This result confirms previous studies that pre-tasks do not contribute to grammatical accuracy (Adams et al., 2014; Ellis, 2005). This might be explained as that drawing mind mapping is an effective meaning-focused cognitive process in which learners' attention is mainly directed to ideas or contents but not to the forms of the language. Thus, the improvement of learners' use of language through mind mapping is not obvious. Another plausible reason is that the experiment only lasts for seven weeks with a primary focus on writing contents and skills, which is extremely limited for the improvement of one's use of language.

In the following interview, it revealed that participants in the experimental group showed a positive attitude towards the application of mind mapping at the pre-writing stage, which was regarded as a useful tool for them to generate ideas and organize the content. It is also found in the interview that use of mind maps may raise learners' interest in English writing and learners begin to regain confidence in English writing tasks. This is in line with previous research that explicit instruction of mind mapping can improve EFL learners' self-efficacy in writing (Behnaz, 2013). While it is also found that there are some difficulties in using mind maps, some students reported that they had to spend more time drawing mind maps in planing before writing and they didn't have enough time for completing the following writing task. This may be due to the fact that the participants in the present study are not skillful in using mind maps in planning. Another possible explanation is that participants are greatly restricted by their present proficiency levels and limited thinking and evaluating abilities. Actually, this is a concern held by Buzan (1993) who regards mind mapping as a time-consuming skill, especially in exams.

\section{Conclusion}

The present study investigated the effects of mind mapping at a pre-writing stage on the written performance of first-year English majors. The results revealed that mind mapping exerted a positive effect on learners' argumentative writing in terms of content and organization. The current findings provided useful insights into writing instruction for Chinese EFL learners.

First, in writing instruction, the mind maps can be used as a tool to help learners approach the topic from the meaning-focused perspective by associating it with their prior knowledge, thus it effectively lowers the cognitive requirement for foreign language learners.Writing is a complex cognitive process, and for EFL learners it is a highly demanding task. Teachers should not only pay attention to students' writing product, but guide students to make plans and direct their attention to the organization of ideas before the actual writing process. In writing class, teachers should explicitly raise students' awareness of using mind maps to improve their writing performance. For example, assign time to students to retrieve and integrate their prior knowledge into the new information. Through discussions of mind maps, teacher may cultivate students' abilities to think diversely and critically and to deepen their understandings of different topics.

Second, Talebinezhad and Negari (2007) put forward that the use of mind mapping can effectively promote students' self-regulation. In the current research, it was found in the interview that explicit instruction of mind mapping as a pre-writing task improved students' confidence in English writing and their negative attitudes towards writing was decreasing. Thus, the implication is that teachers can promote EFL learners' autonomy in practicing writing through mind mapping. For example, on the basis of considering learners' personal interests, teachers may prepare different writing topics and let students choose their one. At the very beginning, teachers should allot enough time for each writing topic and create a relaxed atmosphere in class. After the first training period, students are encouraged to use mind maps to plan and monitor their own writing process.

Due to the small sample size and limited experimental time, the findings of the present study should be interpreted with caution. Further studies should be extended to involve the effects of mind mapping on writing performance of students from different proficiency levels and other individual learners' personal variables should be considered. And more detailed scales should be employed for measuring EFL learners' writing performance. 


\section{Acknowledgments}

This research is supported by "the Fundamental Research Funds for the Central Universities (2015MS68)".

\section{References}

Adams, M. J., Lefkowitz, E. J., King, A. M. Q., \& Carstens, E. B. (2014). Ratification vote on taxonomic proposals to the International Committee on Taxonomy of Viruses. Archives of Virology, 159, 2831-2841. https://doi.org/10.1007/s00705-014-2114-3

Behnaz, N. (2011). The effect of concept mapping on Iranian intermediate EFL Learners' self-efficacy and expository writing accuracy. Theory and Practice in Language Studies, 3(11), 2117-2127.

BejaranoAlcazar, J., BlancoLopez, M. A., MeleroVara, J. M., \& JimenezDiaz, R. M. (1997). The influence of verticillium wilt epidemics on cotton yield in southern Spain. Plant Pathol, 46, 168-178. https://doi.org/10.1046/j.1365-3059.1997.d01-221.x

Bereiter, C., \& Scardamalia, M. (1987). The psychology of written composition. Hillsdale, NJ: Erlbaum.

Buzan, T. (1993). The Mind Map Book. London: BBC Books.

Ellis, N. (2005). At the interface: Dynamic interactions of explicit and implicit language knowledge. Studies in Second Language Acquisition, 27, 305-352. https://doi.org/10.1017/S027226310505014X

Flower, L., \& Hayes, J. R. (1981). A Cognitive process of writing. College Composition and Writing, 32(4), 365-387. https://doi.org/10.2307/356600

Hedge, T. (2000). Teaching and Learning in the Language Classroom. Oxford: Oxford University Press.

Jacobs. H. L., Zinkgraf, S. A., Wormuth, D. R., Hartfiel, V. F., \& Hughhey, J. B. (1981). Testing ESL composition: A practical approach. Rowley, MS: Newbury Cognition House.

Johnson, M. D., Mercado, L., \& Acevedo, A. (2012). The effect of planning sub-processes on L2 writing fluency, grammatical complexity, and lexical complexity. Journal of Second Language Writing, 21, 264-282. https://doi.org/10.1016/j.jslw.2012.05.011

Kellogg, R. T. (1990). Effectiveness of prewriting strategies as a function of task demands. American Journal of Psychology, 103(3), 327-342. https://doi.org/10.2307/1423213

Lee, Y. J. (2013). Collaborative concept mapping as a pre-writing strategy for L2 learning: A Korean application. International Journal of Information and Education Technology, 3(2), 254-258. https://doi.org/10.77 63/IJIET.2013.V3.275

Lee, Y., \& Cho, S. (2010). Concept mapping strategy to facilitate foreign language writing: A Korean application. Retrieved from http://aatk.org/html.

Ojima, M. (2006). Concept mapping a pre-task planning: A case study of three Japanese ESL writers. System, 34(4), 566-585. https://doi.org/10.1016/j.system.2006.08.003

Peregoy, S., \& Boyle, O. (2005). Reading, writing and learning in ESL (4th ed.). Boston: Pearson Education Incorporation.

Pishghadam, R., \& Ghanizadeh, A. (2006). On the impact of concept mapping as a prewriting activity on EFL learners' writing ability. Iranian Journal of applied linguistics, 9(2), 101-126.

Rao, Z. (2007). Training in brainstorming and developing writing skills. ELT Journal, 61(2), 100-106. https://doi.org/10.1093/elt/ccm002

Scane, J., Guy, A. M., \& Wenstrom, L. (1991). Think, write, share: process writing for adult ESL and basic education students. Toronto: The Ontario Institute for Studies in Education.

Shu, X. Y. (2009). An Empirical Research of Application of Mind Map Into English Writing Teaching. Journal of Harbin University, 30(5), 116-121.

Skehan, P., \& Foster, P. (2001). Cognition and task. In P. Robinson (Ed.), Cognition and second language acquisition (pp. 183-205). Cambridge: Cambridge University Press.

Sturm, J. M., \& Rankin-Erikson, J. L. (2002). Effects of hand-drawn and computer-generated concept mapping on the expository writing of middle school students with learning disabilities. Learning Disbilities Research \& Practice, 17(2), 124-139. https://doi.org/10.1111/1540-5826.00039

Sunseri, A. B. (2011). The impact of Thinking Maps on elementary students' expository texts. San Francisco State 
University, United States -- California.

Talebinezhad, M. R., \& Negari, G. M. (2007). The effect of explicit teaching of concept mapping in expository writing on EFL students' self-regulation. The Linguistics Journal, 2(1), 69-90.

Negari, G. M. (2011). A Study on Strategy Instruction and EFL Learners' Writing Skill. International Journal of English Linguistics, 1(2), 299-307. https://doi.org/10.5539/ijel.v1n2p299

Novak, J. D., \& Canas, A. J. (2008). The theory underlying concept maps and how to construct and use them. Retrieved from http://cmap.ihmc.us/Publications/ResearchPapers/TheoryUnderlying ConceptMaps.pd

\section{Copyrights}

Copyright for this article is retained by the author(s), with first publication rights granted to the journal.

This is an open-access article distributed under the terms and conditions of the Creative Commons Attribution license (http://creativecommons.org/licenses/by/4.0/). 